\title{
Internationalization of teacher education
}

\author{
Clementina Acedo
}

Published online: 7 April 2012

(C) UNESCO IBE 2012

Internationalization of teacher education has been a potential issue in comparative education since its early days when scholars such as Jullien de Paris (1775-1848) saw educational transfer as a desirable process. Jullien believed that educational comparisons would "give birth to the idea of borrowing from one another what [...] is good and useful" (Fraser 1964, p. 46). And since its foundation, UNESCO has aimed at supporting good practices in education and teacher education around the world. Working with the International Labour Organization to generate "Recommendations Concerning the Status of Teachers" (ILO/UNESCO 1966), UNESCO established a common reference point that remains relevant in discussions of teachers' work at the local, national, and international levels. The document provides definitions, principles, and guidelines related to teachers' preparation, continuing teacher education, and rights and responsibilities as members of the profession. Moreover, it sets international standards for a wide range of issues, which relate to the most important professional, social, ethical, and material concerns of teachers, including their education. Ever since, UNESCO has also supported the provision of training materials in the area of teacher education and worked to improve the management of teachers through the enhancement of national and comparative teacher data.

Furthermore, the importance of teachers and teacher education has substantially increased in the past few years. A first reason is the growing need for qualified teachers to reach the Education for All (EFA) goals by 2015. But teacher shortages are not only an issue in developing countries, where achieving the EFA goals is most challenging. Many western countries also face problems in recruiting, training, and retaining sufficient qualified teachers. A second reason why well-trained teachers are so significant in current discussions on education is the increased awareness that teachers are one of the most important factors in quality education, if not the most important. This awareness places the issue of training and educating teachers in the limelight. A third reason is the fact that teachers are the most expensive factor in the provision of education, which puts the quality of teachers' work under increased public scrutiny.

C. Acedo $(\triangle)$

UNESCO IBE, P.O. BOX 199, 1211 Geneva 20, Switzerland

e-mail: c.acedo@ibe.unesco.org 
In order to support current challenges related to teachers and teacher education, UNESCO has created several initiatives. Among them are these four:

- It established the Teacher Network of Latin America and the Caribbean (KIPUS). KIPUS was founded in 2003 as a partnership of people and organizations committed to the human and professional development of teachers. The members of the KIPUS Network believe that strengthening the role of teachers is a key element in educational change, and that change is only made possible through the sharing of knowledge, referents, and accumulated experience, and by learning from knowledge generated elsewhere.

- It founded the Teacher Training Initiative for Sub-Saharan Africa (TTISSA) which contributes to improving access, quality, and equity of education through improving the quality and quantity of the teaching force in the region over a period of ten years (2006-2015). TTISSA was established as one of UNESCO's three core initiatives in education.

- It was involved in establishing the International Task Force on Teachers for EFA in 2008; this is an international alliance of EFA partners working together to address the global teacher gap. The task force recognizes the critical role of teachers and aims at coordinating and fostering collaboration on teacher provision worldwide. It adopted an action plan structured around the three major gaps that countries face: a policy gap, a capacity gap, and a financial gap. "Governments [...] should develop a comprehensive national teacher policy covering all levels and forms of education, and addressing teacher education and training, certification, recruitment, deployment, retention and conditions of service including a clear career path" (International Task Force on Teachers for EFA 2011, p. 2).

- The International Bureau of Education (IBE), a UNESCO institute that specializes in curriculum, is currently working jointly with other UNESCO offices, institutes of education, and universities, to implement an accredited postgraduate diploma in curriculum design and development in Africa and in Latin America. This is a conceptual and methodological tool for strengthening the capacities for curricular analysis, design, development, review, and evaluation at the macro, meso and micro levels of the education system, with an emphasis on the school level. The diploma training seeks to bridge the gap between curriculum design and curriculum implementation by targeting teacher educators and teachers. It is based on a resource pack whose design allows it to be used flexibly in a wide range of contexts within an international comparative perspective developed by using case studies from all over the world.

Thus, teachers and teacher education are high on the agendas of international initiatives, efforts at international cooperation, and national policy-makers alike. In many projects and programmes that aim at educational development and reform, international policies or standards are transferred and teachers often receive further foreign-funded training or undergo training in a foreign country. However, both practical experience and evidence in the literature suggest that the process of implementing sustainable processes in teacher training can be riddled with difficulties, especially as programmes often fail to sufficiently acknowledge the diversity of local policy and teaching contexts.

This Open File of Prospects therefore focuses on specific cases in the internationalization of teacher education, discussing trends in several countries and the role that international actors and discourses play in teacher education policies and practices. 


\section{References}

Fraser, S. E. (1964). Jullien's plan for comparative education, 1816-1817. New York: Teachers College, Columbia University.

ILO/UNESCO (1966). Recommendation concerning the status of teachers. Paris: UNESCO.

International Task Force on Teachers for EFA (2011). Communiqué of the international conference on teachers for EFA in Africa: Collaborative action to address the teacher gap. Nairobi, Kenya, January 19-20, 2011. http://www.teachersforefa.unesco.org/en/Resources/All/Communique\%20Conference_ EN.pdf. 